Roger Williams University

DOCS@RWU

1992

\title{
Fluorescence quenching in the varied photosynthetic modes of Portulacaria afra (L.) Jacq
}

Lonnie J. Guralnick

Roger Williams University, Iguralnick@rwu.edu

Guillermo Goldstein

Robert L. Heath

Irwin P. Ting

Follow this and additional works at: https://docs.rwu.edu/fcas_fp

Part of the Biology Commons

\section{Recommended Citation}

Guralnick LJ, Guillermo Goldstein, Robert L. Heath, Irwin P. Ting. 1992. "Fluorescence quenching in the varied photosynthetic modes of Portulacaria afra (L.) Jacq." Plant Physiol. 99 (4):1309-1313.

This Article is brought to you for free and open access by the Arts and Sciences at DOCS@RWU. It has been accepted for inclusion in Arts \& Sciences Faculty Publications by an authorized administrator of DOCS@RWU. For more information, please contact mwu@rwu.edu. 


\title{
Fluorescence Quenching in the Varied Photosynthetic Modes of Portulacaria afra (L.) Jacq.
}

\author{
Lonnie J. Guralnick, Robert L. Heath, Guillermo Goldstein, and Irwin P. Ting * \\ Division of Natural Sciences and Mathematics, Western Oregon State College, Monmouth, Oregon 97361 (L.J.G.); \\ Department of Botany and Plant Sciences, University of California, Riverside, California 92521 (R.L.H., I.P.T.); \\ and Laboratory of Biomedical and Environmental Sciences, University of California, \\ Los Angeles, California 90024 (G.G.)
}

\begin{abstract}
The kinetics of chlorophyll fluorescence were measured in Portulacaria afra (L.) Jacq. when the plants were functioning in either Crassulacean acid metabolism (CAM) or $\mathrm{C}_{3} / \mathrm{CAM}$ cycling (called cycling) modes, as determined by fluctuation in titratable acidity and gas exchange properties. Cycling plants showed primarily daytime $\mathrm{CO}_{2}$ uptake typical of $\mathrm{C}_{3}$ plants, but with a slight diurnal acid fluctuation, whereas CAM plants showed nocturnal $\mathrm{CO}_{2}$ uptake, daytime stomatal closure, and a large diurnal acid fluctuation. Results from fluorescence measurements indicated no significant differences in photochemical quenching between cycling and CAM plants; however, sizable differences were detected in nonphotochemical quenching $\left(q_{N}\right)$, with the largest differences being observed during the middle of the day. Cycling plants had lower $q_{N}$ than CAM plants, indicating altered photosynthetic regulation processes. This $q_{N}$ difference was believed to be related to reduced internal $\mathrm{CO}_{2}$ concentration in the CAM plants because of daytime stomatal closure and reduced deacidification rates in the late afternoon when most of the malic acid has been utilized. Experimentally, higher external $\mathrm{CO}_{2}$ given to plants in the CAM mode resulted in a decline in $q_{N}$ in comparison to that measured in plants in the cycling mode. No changes were observed in photochemical quenching when $\mathrm{CO}_{2}$ was added.
\end{abstract}

Many studies of CAM species have focused on the shift from $\mathrm{C}_{3} / \mathrm{CAM}$ cycling (called cycling) to CAM photosynthesis during various stresses $(3,8,9,17,21,23)$. These facultative CAM plants change their metabolism from daytime $\mathrm{CO}_{2}$ uptake with little or no organic acid fluctuations (similar to plants undergoing $\mathrm{C}_{3}$ photosynthesis) to nocturnal $\mathrm{CO}_{2}$ uptake with daytime stomatal closure and a larger fluctuation in the organic acid pool, typical of $\operatorname{CAM}(12,13,23)$.

Variable $\mathrm{Chl}$ fluorescence has been used in the past as a noninvasive tool to study the CAM photosynthetic pathway. The amount of variable fluorescence in Kalanchoe daigremontiana, Ananas comosus, and Opuntia stricta changed from morning to evening in concert with the deacidification of the tissue $(6,16)$. Chl fluorescence with light scattering (a putative measure of the $\mathrm{H}^{+}$fluxes within the chloroplast) has been used to study the day/night cycle of CAM in $K$. pinnata (15).

\footnotetext{
${ }^{1}$ This research was supported, in part, by National Science Foundation grant DCB-8807860 (to I.P.T).
}

The Chl fluorescence transients correlated with increased light scattering. On the other hand, the results of Buschmann and Buchanan-Bollig (4) indicated that Chl fluorescence transients were dependent upon leaf structure, pigment composition, and the organization of the photosystems rather than the $\mathrm{CO}_{2}$ fixation pathway. The question arises as to how well control of the operation of photosynthesis by internal $\mathrm{CO}_{2}$ levels (7) can be measured by fluorescence techniques. The levels of $\mathrm{CO}_{2}$ inside the leaf certainly change between these two photosynthetic modes (5) and so should alter photosynthesis and, concurrently, the fluorescence patterns (18).

A fluorescence technique has been developed that enables the separation of $\mathrm{q}_{\mathrm{p}}{ }^{2}$ and $\mathrm{q}_{\mathrm{N}}$ quenching of Chl fluorescence (20). This technique uses a weak light beam to measure the fluorescence yield and a high intensity actinic beam to drive photosynthesis. The application of a second light pulse of high intensity is used to overwhelm photochemical quenching, thus permitting direct measurement of $q_{N}$. This technique was used here to monitor changes in $\mathrm{q}_{\mathrm{p}}$ and $\mathrm{q}_{\mathrm{N}}$ in Portulacaria afra (L.) Jacq. (a facultative CAM plant) as it shifted from cycling to the CAM mode of photosynthesis under water stress $(9,13)$ and, in part, to show how internal $\mathrm{CO}_{2}$ was changing during the metabolic switch. The critical factor in these experiments is that this shift was not accompanied by any changes in pigment composition (11). The effect of external $\mathrm{CO}_{2}$ levels on these same fluorescence measurements was also examined.

\section{MATERIALS AND METHODS}

\section{Plant Material}

Portulacaria afra (L.) Jacq. plants were propagated by cuttings from a large shrub growing on the University of California, Riverside, campus. The cuttings were rooted and grown in 2-gallon pots containing loamy sand potting mix. Plants in the cycling mode were watered three times per week and fertilized bimonthly with half-strength Hoagland solution (10). CAM was induced by withholding water during the summer for 2 weeks prior to experimentation. All plants were grown in a glasshouse with a mean high temperature

\footnotetext{
${ }^{2}$ Abbreviations: $q_{p}$, photochemical quenching; $q_{N}$, nonphotochemical quenching; $F_{0}$, initial fluorescence (dark adapted); $F_{0}{ }^{\prime}$, initial fluorescence (light adapted); $F_{m}$, peak fluorescence (dark adapted); $F_{m}{ }^{\prime}$, peak fluorescence (light adapted).
} 
of $28^{\circ} \mathrm{C}$ and a mean low of $18^{\circ} \mathrm{C}$ under natural illumination conditions (maximum photon flux density, $800 \mu \mathrm{mol} \mathrm{m}^{-2} \mathrm{~s}^{-1}$ ) during the summer months of June through August. All leaves used were mature and fully expanded.

\section{Titratable Acidity}

Twelve to sixteen leaves were collected at various times and frozen $\left(-20^{\circ} \mathrm{C}\right)$ until assayed (10). Leaf punches $(0.24$ $\mathrm{cm}^{2}$ ) obtained with a cork borer were ground in glass-distilled water with a tissue grinder. Samples were then titrated with $0.01 \mathrm{~N} \mathrm{KOH}$ to an endpoint of $\mathrm{pH} 7.0$. Results are expressed as $\mu \mathrm{eq} \mathrm{cm}^{-2}$ ( $\pm \mathrm{SE}, n=5$ ).

\section{Gas Exchange}

The diurnal course of $\mathrm{CO}_{2}$ uptake and stomatal conductance was measured with the use of a dual isotope porometer, as previously described (10), with five samples for each time point. These unidirectional conductance measurements were converted to transpiration and photosynthetic rates, also as previously described (10).

\section{Chl Fluorescence}

Fluorescence was measured using the Hansatech Modulated Fluorescence System (Decagon, Pullman, WA). This system utilizes a continuous yellow low-intensity beam of $0.6 \mu \mathrm{mol} \mathrm{m} \mathrm{m}^{-2} \mathrm{~s}^{-1}$ to continuously monitor the fluorescence yield. This light intensity produces no changes in the yield, and so the yield thus induced is taken as $F_{0}$. A second beam of nonmodulated light (white light of high intensity, 320 $\mu \mathrm{mol} \mathrm{m} \mathrm{m}^{-2} \mathrm{~s}^{-1}$ ) required to drive the photochemistry is added to induce an increase in fluorescence yield $(F)$. At 20-s intervals, a third light beam is applied as a pulse (duration of $0.3 \mathrm{~s})$ with saturating intensity $\left(1530 \mu \mathrm{mol} \mathrm{m} \mathrm{m}^{-2} \mathrm{~s}^{-1}\right)$. The application of this pulse allows for the measurement of the flash-saturated fluorescence yield called the peak value of fluorescence (light adapted, $F_{m}{ }^{\prime}$ ) and, under certain conditions, of maximum fluorescence (dark adapted, $F_{m}$ ) (see Fig. 2). Light intensity curves for these plants while in the $C_{3}$ mode indicate that $\mathrm{CO}_{2}$ uptake was saturated between 1000 and $1200 \mu \mathrm{mol} \mathrm{m}^{-2} \mathrm{~s}^{-1}$.

The pulse measurements to determine the values of $F_{m}{ }^{\prime}$ and $F_{m}$ were taken at the 10 th pulse after which these values were unchanging. This allowed for the determination of $q_{p}$ and $\mathrm{q}_{\mathrm{N}}$ with the use of Equations 1 and 2, taken from Kooten and Snel (14);

$$
\begin{gathered}
\mathrm{q}_{\mathrm{p}}=\left[F_{m}{ }^{\prime}-F\right] /\left[F_{m}{ }^{\prime}-F_{0}{ }^{\prime}\right] \\
\mathrm{q}_{\mathrm{N}}=1-\left[F_{m}{ }^{\prime}-F_{0}{ }^{\prime}\right] /\left[F_{m}-F_{0}\right]
\end{gathered}
$$

Leaves of $P$. afra in either the cycling or CAM mode were harvested at 2 - $h$ intervals during the day and utilized immediately for the fluorescence measurements (each experimental sequence required about 6-8 $\mathrm{min}$ ). Detached succulent leaves of $P$. afra have previously been shown to have photosynthetic rates similar to those of attached leaves (10); thus, it was assumed detachment would have a minimal effect on fluorescence. Experimental results supported this assumption.
The standard statistical test of a two-way analysis of variance was applied to timed paired datum points, where applicable, with a level of $5 \%$ or less being taken as significant.

\section{$\mathrm{CO}_{2}$ Supplementation}

To elevate the internal $\mathrm{CO}_{2}$ concentration, some leaves harvested for the fluorescence kinetics were exposed to air containing $1000 \mathrm{ppm} \mathrm{CO}_{2}$. The $\mathrm{CO}_{2}$ supplementation was done in the afternoon during the transition from phase III to phase IV of the $\mathrm{CO}_{2}$ diurnal uptake pattern (see ref. 16 for a definition of CAM phases). These leaves were placed in a polyethylene chamber with an air/ $\mathrm{CO}_{2}$ mixture flowing through water-saturated gauze for $5 \mathrm{~min}$ before the beginning of the fluorescence measurement. In similar experiments, $\mathrm{CO}_{2}$ was blown directly onto the leaves placed in the fluorometer during the fluorescence measurements. There were no differences noted in these two types of experiments.

\section{RESULTS}

\section{Gas Exchange and Titratable Acidity}

The kinetics of gas exchange for well-watered $P$. afra showed a modified $C_{3}$ pattern called CAM cycling or cycling (21), which is marked by predominantly daytime gas exchange with a midday depression of $\mathrm{CO}_{2}$ uptake (Fig. 1A, $+\mathrm{H}_{2} \mathrm{O}$ ). Nocturnal $\mathrm{CO}_{2}$ uptake was absent at the beginning of the night period, but increased slightly during the last $6 \mathrm{~h}$ of night. Titratable acidity showed a small diurnal fluctuation of 17 to $20 \mu \mathrm{eq} \mathrm{cm}^{-2}$, which is typical of $P$. afra (Fig. 1B, $+\mathrm{H}_{2} \mathrm{O}$; also see ref. 13).

On the other hand, water-stressed $P$. afra plants showed a typical CAM pattern (Fig. $1 \mathrm{~A},-\mathrm{H}_{2} \mathrm{O}$ ) in which $\mathrm{CO}_{2}$ uptake was highest at sunrise $(0600 \mathrm{~h})$ and dropped to near 0 by $0800 \mathrm{~h}$. There was little $\mathrm{CO}_{2}$ uptake for the remainder of the day. $\mathrm{CO}_{2}$ uptake became apparent at the beginning of the night period, reaching a maximum by night's end. Titratable acidity showed a large diurnal fluctuation of $40 \mu \mathrm{eq} \mathrm{cm}^{-2}$ (Fig. 1B). Diurnal acid fluctuations were occasionally smaller, but they were always larger than those of the plants in the cycling mode.

\section{Fluorescence}

The Chl fluorescence curves showed two distinct patterns (Fig. 2). The measuring beam elicited a small signal $\left(F_{0}\right)$, which was the same for cycling and for CAM. The lightdriven change in fluorescence yield rose to a peak $\left(F_{m}\right)$ in about 1 to $2 \mathrm{~s}$, and then decayed to a relatively low value, slightly above $F_{0}$ for both types of plants. The only obvious difference in kinetics between cycling and CAM plants was the appearance of a small, variable peak at about 2 min (called " $\mathrm{M}$ " phase in older nomenclature) for plants in the cycling mode. A short light pulse increased the yield to a maximum level $\left(F_{m}^{\prime}\right)$, which rapidly returned to $\mathrm{F}$ after the cessation of the pulse (within $0.5 \mathrm{~s}$ ).

The kinetics of these pulses enable the calculation of diurnal patterns of $\mathrm{q}_{\mathrm{p}}$ and $\mathrm{q}_{\mathrm{N}}$ for $P$. afra in each metabolic mode. A stable $q_{p}$ value was reached at $0800 \mathrm{~h}, 2 \mathrm{~h}$ after sunrise (Fig. 3). The $q_{p}$ values for the well-watered plants (in the 

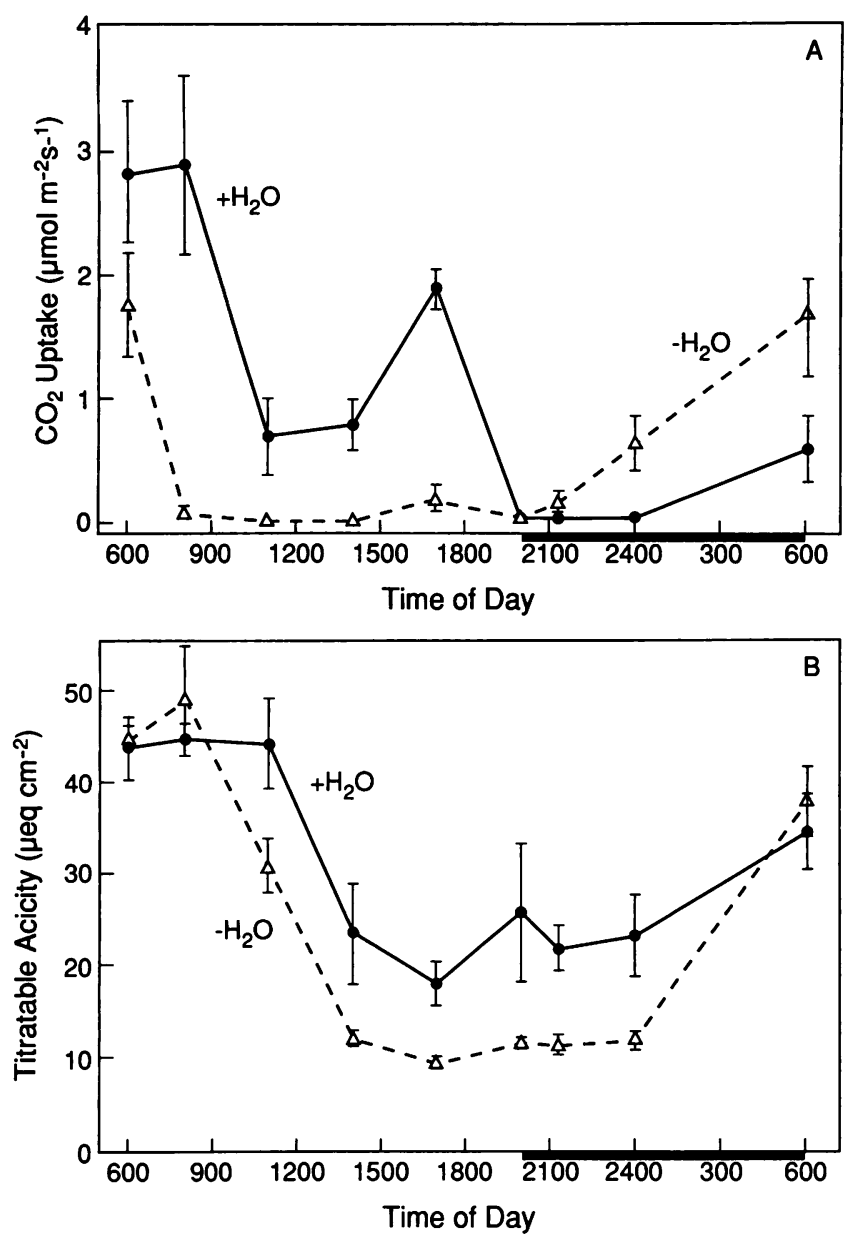

Figure 1. The metabolic parameters characteristic of the cycling and the CAM modes for $P$. afra. The $\mathrm{CO}_{2}$ uptake rate and leaf acidity were measured and calculated as described in "Materials and Methods." A, $\mathrm{CO}_{2}$ uptake. A typical diurnal curve of carbon uptake activity. B, Acidity present within the leaf. A typical diurnal curve of titratable acidity. $+\mathrm{H}_{2} \mathrm{O}$, data from well-watered plants showing cycling; $-\mathrm{H}_{2} \mathrm{O}$, data from water-stressed plants showing CAM. Error bars represent $1 \mathrm{SE}(n=6)$.

cycling mode) were usually slightly lower than those of the plants in the CAM mode; however, the difference between the $\mathrm{q}_{\mathrm{N}}$ curves was very small and only slightly above the $5 \%$ level statistically.

The largest differences were observed in $\mathrm{q}_{\mathrm{N}}$ values. In both cycling and CAM, the $\mathrm{q}_{\mathrm{N}}$ values were highest early in the morning, but dropped over the course of the day, rising slightly at sunset, especially for the well-watered plants. Plants in the CAM mode showed $\mathrm{q}_{\mathrm{N}}$ values that were typically slightly higher than those of the plants in the cycling mode during the morning hours (0800-1200 h) and significantly higher in the mid-afternoon hours (1600-1800 h).

In the above experiments, leaves were collected in the greenhouse at the indicated time and transported back to the laboratory for the fluorescence measurements (requiring about $5 \mathrm{~min}$ ); it was thought that dark adaptation of leaves would give a more reproducible signal. Yet, under these circumstances, it seemed that the transportation and dark

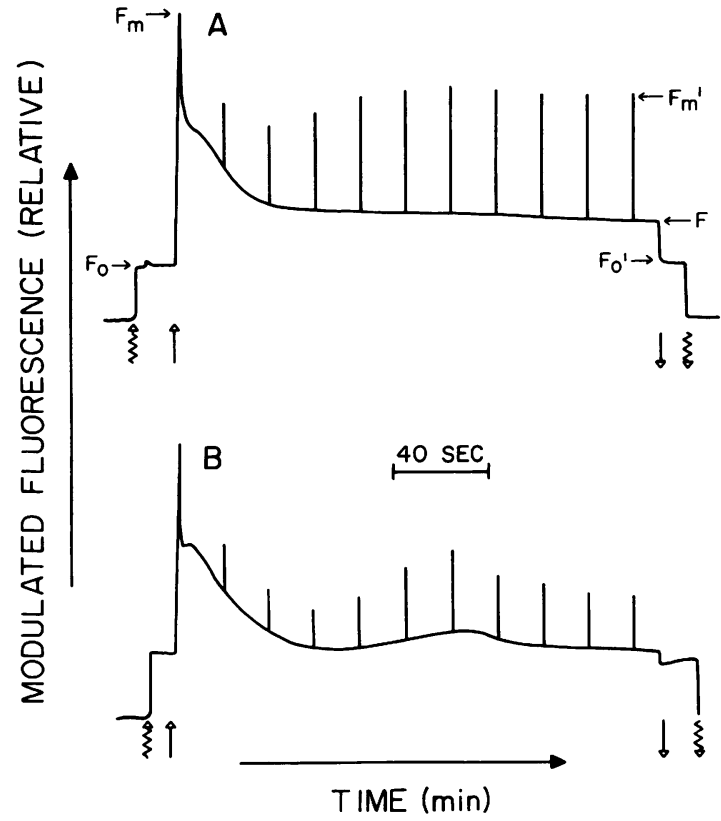

Figure 2. Typical modulated fluorescence signals from $P$. afra leaves in CAM induced by water-stress (A) and cycling (B) modes. Arrows denote onset of modulated light (wavy line), or high intensity actinic light (straight line); upward is light on, downward is light off. The spike of fluorescence yield is caused by a second actinic light given as a pulse (see "Materials and Methods"). Values of $F_{0}, F_{0}{ }^{\prime}, F_{m}, F_{m}$ ', and $F$ used in Equations 1 and 2 are indicated on curve $A$.

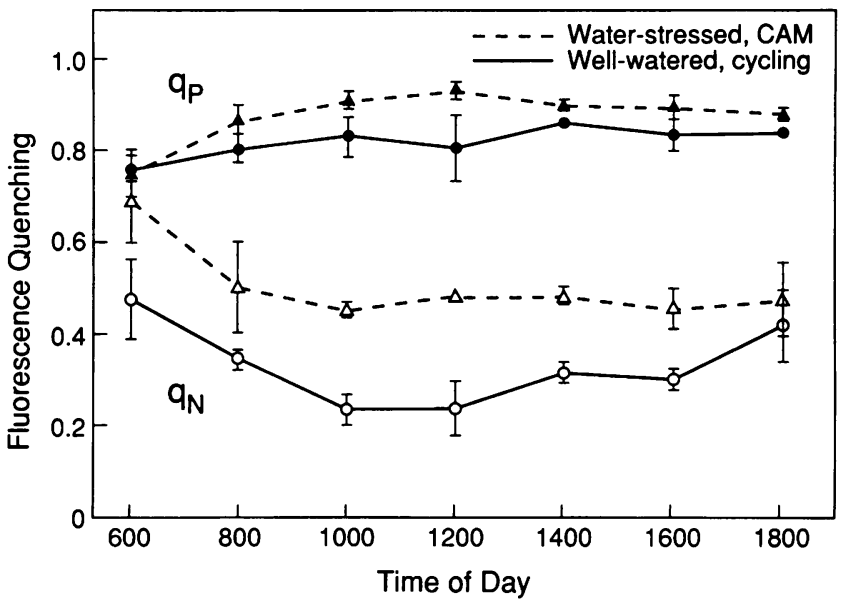

Figure 3. Levels of fluorescence quenching mechanisms in darkadapted $P$. afra. The plants were shifted to either cycling (wellwatered, solid line; $O, O$ ) or to CAM (drought-stressed, dotted lines; $\Delta, \mathbf{\Delta})$. The experiments were conducted in the dark. The levels of $\mathrm{q}_{\mathrm{p}}$ (closed symbols) and $\mathrm{qN}$ (open symbols) were measured as described in "Materials and Methods." The data were taken after a dark period of greater than 5 min. Results of four experiments. 
adaptation were introducing more variation into the measurements.

Indeed, the $\mathrm{q}_{\mathrm{N}}$ difference between CAM and cycling plants noted above became larger with the elimination of a dark adaptation time (Fig. 4). The fluorometer was moved to the greenhouse and the fluorescence from leaves was measured immediately (within $1 \mathrm{~min}$ ). During midday, the difference observed in $\mathrm{q}_{\mathrm{N}}$ between well-watered and water-stressed plants was then accentuated. From 1000 to $1200 \mathrm{~h}$, there was a larger difference in $\mathrm{q}_{\mathrm{N}}$ values. Also, the small difference in $\mathrm{q}_{p}$ values apparently reversed; the $\mathrm{q}_{\mathrm{p}}$ is lower in CAM plants when measurements were taken on leaves that had not been dark adapted.

\section{$\mathrm{CO}_{2}$ Supplementation}

One source for the difference in $\mathrm{q}_{\mathrm{N}}$ values between cycling and CAM plants may be in a difference in internal $\mathrm{CO}_{2}$ levels in the two modes $(5,18)$. To test this idea, the $\mathrm{CO}_{2}$ level of the atmosphere around plants in both modes of metabolism was increased from 330 to $1000 \mu \mathrm{L} \mathrm{L}^{-1}$. This supplementation was carried out in the afternoon, when the plants showed the maximum difference in $\mathrm{q}_{N}$. As seen in Table $I$, this addition of $\mathrm{CO}_{2}$ to plants in the CAM mode significantly lowered the $\mathrm{q}_{\mathrm{N}}$ value so that the new level was closer to that of well-watered plants. Thus, $\mathrm{CO}_{2}$ seems to be an important factor influencing the $\mathrm{q}_{\mathrm{N}}$ level, and these data suggested that the $\mathrm{CO}_{2}$ within these CAM plants was limiting to photosynthesis. In contrast, the higher levels of $\mathrm{CO}_{2}$ supplied to wellwatered plants induced no apparent trend.

\section{DISCUSSION}

Gas exchanges observed in these experiments were typical for either the cycling or the CAM modes in $P$. afra $(9,12)$. The cycling plants showed a pattern of gas exchange termed CAM cycling by Ting (21), with daytime gas exchange and

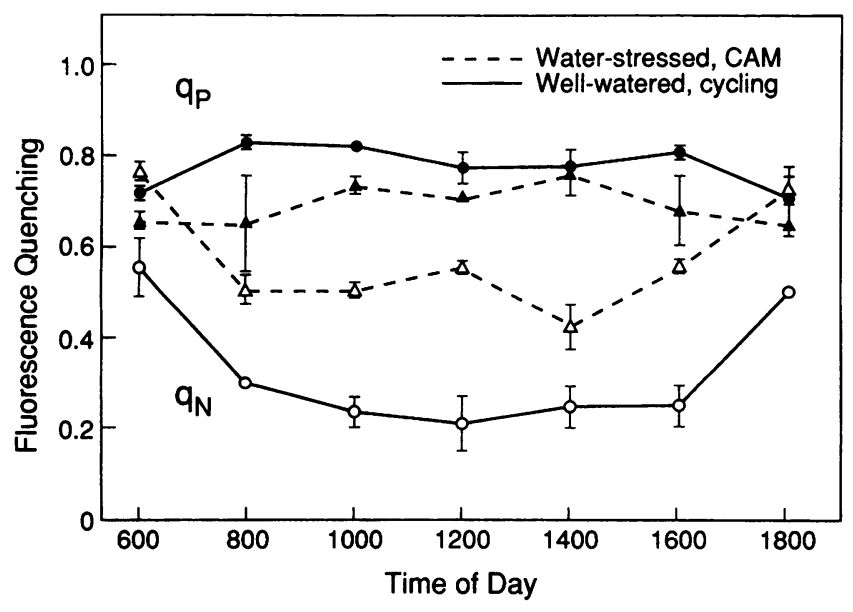

Figure 4. Levels of fluorescence quenching in $P$. afra plant leaves immediately after light exposure. The data were collected and presented as in Figure 3, except that the leaves were held in room light for less than $1 \mathrm{~min}$ after removal from daylight. Results of two experiments.
Table I. Change in $q_{\mathrm{N}}$ after $\mathrm{CO}_{2}$ Supplementation in P. afra Undergoing CAM

\begin{tabular}{cc}
\hline Treatment & Decline $\left(\%\right.$ Change $\left.^{\mathrm{a}}\right)$ \\
\hline Dark adapted $(5 \mathrm{~min})$ & $+9.0(6.0)^{\mathrm{b}}$ \\
No dark adaptation & $+19.5(8.9)^{\mathrm{c}}$ \\
\hline
\end{tabular}

${ }^{a}$ Change in $q_{N}$ is defined as $\left(\left[q_{N}\right.\right.$ prior $-q_{N}$ after $\mathrm{CO}_{2}$ supplementation]/ $q_{N}$ prior). Values are means $\pm \mathrm{SE} . \quad{ }^{\mathrm{b}}$ Change in $\mathrm{q}_{\mathrm{N}}$ not significantly different from 0 at $P<0.05(P=.075, n=$ 19). $\quad{ }^{c}$ Change in $q_{N}$ significantly different from 0 at $P<0.05(n$ $=8)$.

low diurnal acid fluctuations resulting primarily from the recycling of nocturnal respiratory $\mathrm{CO}_{2}$. The $P$. afra in the CAM mode showed a much higher daily acid fluctuation, daytime closure and nocturnal opening of stomata, and nocturnal $\mathrm{CO}_{2}$ uptake typical of CAM plants (13).

The pulsed-light fluorescence technique enables partitioning of fluorescence into $q_{p}$ and $q_{N}(14,20)$. $q_{p}$ is due to the reduction of $Q$, the primary electron acceptor of PSII $(2,20)$. $\mathrm{q}_{\mathrm{N}}$ is thought to be due, in part, to a transthylakoid $\mathrm{pH}$ gradient $(2,20)$. High rates of $\mathrm{CO}_{2}$ fixation, due to a high internal $\mathrm{CO}_{2}$ level, would result in faster utilization of ATP and NADPH and a decrease in the transthylakoid $\mathrm{pH}$ gradient; the combined effect of these processes upon the fluorescence would be a lowering of $\mathrm{q}_{\mathrm{N}}$ and, possibly, a slight increase in $q_{p}(19,22)$. On the other hand, a lower concentration of internal $\mathrm{CO}_{2}$ would slow $\mathrm{CO}_{2}$ fixation and thus give rise to a high level of $\mathrm{q}_{\mathrm{N}}$ and, possibly, to a low level of $\mathrm{q}_{\mathrm{p}}$. The exact relations depend upon how close the $\mathrm{CO}_{2}$ level is to saturating the critical enzymes.

Our results indicated little difference in $\mathrm{q}_{\mathrm{p}}$ between cycling and CAM $P$. afra, yet the changes are consistent with the above for plants that have not been dark adapted (Fig. 4). The small differences in $\mathrm{q}_{\mathrm{p}}$ cannot be explained by changes in $\mathrm{Chl}$ content because $\mathrm{Chl}$ remains constant between cycling and CAM when the latter is induced by short-term water deprivation in $P$. afra (11).

The largest fluorescence difference between cycling and CAM was observed in $\mathrm{q}_{\mathrm{N}}$ and appears to be related to the $\mathrm{CO}_{2}$ fixation pathway. CAM plants had a higher $\mathrm{q}_{\mathrm{N}}$ throughout the day. The differences in $\mathrm{q}_{\mathrm{N}}$ between cycling and CAM plants were smaller in the early morning, possibly reflecting the high deacidification rates in $P$. afra undergoing CAM and, thus, higher levels of internal $\mathrm{CO}_{2}$ (5). Deacidification rates between 0800 and $1200 \mathrm{~h}$ can reach from 8 to $12 \mu \mathrm{mol} \mathrm{m}{ }^{-2}$ $\mathrm{s}^{-1}$, similar to exogenous $\mathrm{CO}_{2}$ uptake rates in cycling $P$. afra (12). In the early morning and late afternoon, $q_{N}$ values in both cycling and CAM $P$. afra rose, which indicated that rates of $\mathrm{CO}_{2}$ fixation were lower due to limitations in light intensity.

The largest difference in $\mathrm{q}_{\mathrm{N}}$ between cycling and CAM was observed during the middle of the day. These results correlate with the changes in light scattering found in K. pinnata, where the decline in scattering (correlating with higher consumption of ATP) during the middle of the day was smaller than that measured at the beginning or end of the light period (15). However, we believe that this difference in $q_{N}$ is related to differences in $\mathrm{CO}_{2}$ fixation and, in the main, to differences 
in internal $\mathrm{CO}_{2}$ level. Cycling plants have two sources of $\mathrm{CO}_{2}$ during the middle of the day, atmospheric $\mathrm{CO}_{2}$ and malic acid decarboxylation. A lower $\mathrm{q}_{\mathrm{N}}$ in the cycling plants, compared to that of CAM plants, is consistent with the notion that an increased supply of $\mathrm{CO}_{2}$ within the leaf leads to faster $\mathrm{CO}_{2}$ fixation. In CAM plants, higher $\mathrm{q}_{\mathrm{N}}$ was probably related to stomatal closure, which restricted the supply of exogenous $\mathrm{CO}_{2}$, coupled with the declining deacidification rate due to a depletion of malic acid within the cell.

$\mathrm{CO}_{2}$ depletion can close stomata, but there can be more than one signal involved. It is known that $\mathrm{ABA}$ from roots (24) can make stomata more sensitive to $\mathrm{Ca}^{2+}$, which influences stomatal conductance (1). Thus, the closure of stomata in CAM plants could be due to a combination of signals and not just to $\mathrm{CO}_{2}$. As the internal $\mathrm{CO}_{2}$ level drops during the day through depletion of the acidity and its associate $\mathrm{CO}_{2}$ production, $\mathrm{q}_{\mathrm{N}}$ declines. In $\mathrm{CAM}$, neither $\mathrm{CO}_{2}$ nor $\mathrm{q}_{\mathrm{N}}$ declines as low as for cycling plants. There, $\mathrm{q}_{\mathrm{N}}$ is very low because internal $\mathrm{CO}_{2}$ is lower than ambient concentrations during active photosynthesis.

We tested this idea by supplementing $\mathrm{CO}_{2}$ to $\mathrm{CAM}$ leaf tissue in the afternoon, when $\mathrm{q}_{\mathrm{N}}$ differences were observed to be the greatest. Higher external $\mathrm{CO}_{2}$ shifted the value of $\mathrm{q}_{\mathrm{N}}$ to a more cycling-like value, i.e. lowered it. Yet it was difficult to obtain significant results if a dark adaptation time was allowed; this may reflect either a deactivation of $\mathrm{CO}_{2}$ fixation or a reversal of photoinhibition. However, data taken without dark adaptation also supported the above concept of limiting internal $\mathrm{CO}_{2}$ within CAM plants.

Our results may explain differences observed in simple fluorescence kinetics in the cycling mode and for the CAM mode in Sedum spectabile (4) and in K. daigremontiana (6). Also, the induction kinetics in the CAM plant Ananas comosus demonstrating only $Q$ reduction showed no correlation with the CAM pathway (6). Our results, likewise, indicated little or no difference in photochemical quenching, nor in induction kinetics. All of these results indicate that in experiments in which only photochemical quenching is observed, it is found not to correlate well with internal $\mathrm{CO}_{2}$ levels or with CAM metabolism.

The pulsed fluorescence technique can provide information on the difference in the energy status between cycling and CAM $P$. afra plants that a simple variable fluorescence technique does not readily detect. The pulse fluorescence technique is relatively easy to use and should become a useful research tool with which to study the energetic relationships in photosynthetic carbon metabolism.

\section{LITERATURE CITED}

1. Atkinson CJ, Mansfield TA, Kean AM, Davies WJ (1989) Control of stomatal aperture by calcium in isolated epidermal tissue and whole leaves of Commelina communis L. New Phytol 111: 9-17

2. Baker NR, Horton $P$ (1987) Chlorophyll fluorescence quenching during photoinhibition. In DJ Kyle, CB Osmond, CJ Arntzen, eds, Photoinhibition. Elsevier Science Publishers, New York, pp 145-168

3. Bartholomew B (1973) Drought response in the gas exchange of Dudleya farinosa (Crassulaceae) grown under natural conditions. Photosynthetica 7: 114-120

4. Buschmann C, Buchanan-Bollig IC (1983) Changes of the chlorophyll fluorescence induction kinetics of $\mathrm{C}_{3}$ and CAM plants during day/night cycles. Photosynth Res 4: 337-349

5. Cockburn W, Ting IP, Sternberg LO (1979) Relationships between stomatal behavior and internal carbon dioxide concentration in Crassulacean acid metabolism plants. Plant Physiol 63: $1029-1032$

6. Everson G, Chen SS, Black CC Jr (1983) Diurnal variations in leaf fluorescence induction kinetics. Plant Physiol 72: 455-460

7. Farquhar GD, Sharkey TD (1982) Stomatal conductance and photosynthesis. Annu Rev Plant Physiol 33: 317-345

8. Guralnick LJ, Rorabaugh PA, Hanscom Z (1984) Influence of photoperiod and leaf age on Crassulacean acid metabolism in Portulacaria afra (L.) Jacq. Plant Physiol 75: 454-457

9. Guralnick LJ, Rorabaugh PA, Hanscom Z (1984) Seasonal shifts of photosynthesis in Portulacaria afra (L.) Jacq. Plant Physiol 76: 643-646

10. Guralnick LJ, Ting IP (1986) Seasonal response to drought and rewatering in Portulacaria afra (L.) Jacq. Oecologia 70: 85-91

11. Guralnick LJ, Ting IP (1987) Physiological changes in Portulacaria afra (L.) Jacq. during a summer drought and rewatering. Plant Physiol 70: 85-91

12. Guralnick LJ, Ting IP (1988) Seasonal patterns of water relations and enzyme activity of the facultative CAM plant Portulacaria afra (L.) Jacq. Plant Cell Environ 11: 811-818

13. Hanscom Z, Ting IP (1978) Response of succulents to plant water stress. Plant Physiol 61: 327-330

14. Kooten O, Snell JFH (1990) The use of chlorophyll fluorescence nomenclature in plant stress physiology. Photosynth Res 25: 147-150

15. Koster S, Winter K (1985) Light scattering as an indicator of the energy state in leaves of the Crassulacean acid metabolism plant Kalanchoë pinnata. Plant Physiol 79: 520-524

16. Osmond CB (1982) Carbon cycling and stability of the photosynthetic apparatus. In IP Ting, M Gibbs, eds, Crassulacean Acid Metabolism. Am Soc Plant Physiol, Rockville, MD, pp 112-127

17. Queiroz O (1974) Circadian rhythms and metabolic patterns. Annu Rev Plant Physiol 25: 114-134

18. Peterson RB, Sivak MN, Walker DA (1988) Relationship between steady-state fluorescence yield and photosynthetic efficiency in spinach leaf tissue. Plant Physiol 88: 158-163

19. Schreiber $U$, Bilger $W$ (1987) Rapid assessment of stress effects on plant leaves by chlorophyll fluorescence measurements. In JD Tenhunen, FM Catarino, OL Lange, WL Oechel, eds, Plant Response to Stress. Springer-Verlag, Berlin, pp 27-53

20. Schreiber U, Schliwa U, Bilger $W(1986)$ Continuous recording of photochemical and nonphotochemical chlorophyll fluorescence quenching with a new type of modulation fluorometer. Photosynth Res 10: 51-62

21. Ting IP (1985) Crassulacean acid metabolism. Annu Rev Plant Physiol 36: 595-622

22. Winter K, Demmig B (1987) Reduction state of $Q$ and nonradiative energy dissipation during photosynthesis in leaves of a Crassulacean acid metabolism plant, Kalanchoë diagremontiana Hamet et Perr. Plant Physiol 85: 1000-1007

23. Winter K, Lüttge U, Winter E, Troughton JH (1978) Seasonal shift from $\mathrm{C}_{3}$ photosynthesis to Crassulacean acid metabolism in Mesembryanthemum crystallinum growing in its natural environment. Oecologia 34: 225-237

24. Zhang J, Davies WJ (1989) Sequential response of whole plant water regulations to prolonged soil drying and the involvement of xylem sap ABA in the regulation of stomatal behavior of sunflower plants. New Phytol 113: 167-174 